・论坛・ 中国国家公园试点专题

\title{
完善国家公园管理体制的建议
}

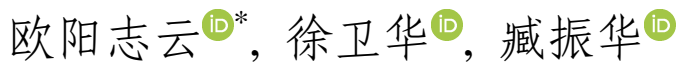

中国科学院生态环境研究中心城市与区域生态国家重点实验室, 北京 100085

欧阳志云, 徐卫华, 藏振华 (2021) 完善国家公园管理体制的建议. 生物多样性, 29, 272-274. doi: 10.17520/biods.2021083.

Ouyang ZY, Xu WH, Zang ZH (2021) Suggestions on improving the management system of national parks. Biodiversity Science, 29, 272-274. doi: 10.17520/biods.2021083.

\section{Suggestions on improving the management system of national parks}

Zhiyun Ouyang ${ }^{(\mathbb{D} *}$, Weihua $\mathrm{Xu}^{(\mathbb{D})}$, Zhenhua Zang

State Key Laboratory of Urban and Regional Ecology, Research Center for Eco-Environmental Sciences, Chinese Academy of Sciences, Beijing 100085

建立国家公园体制是习近平生态文明思想的 重大理论和实践创新, 对于推进自然资源的科学保 护和合理利用、促进人与自然和谐共生、推进美丽 中国建设具有极其重要的意义。自2015年12月起, 我国陆续启动了三江源、神农架、武夷山等10个国 家公园体制试点(唐芳林等, 2019; 藏振华等, 2020)。国家公园体制试点承担着破解我国自然保护 地发展过程中存在的多头管理、权责不明、保护与 发展矛盾突出等问题的重要使命。目前试点建设取 得阶段性进展, 统一分级的管理体制初步建立, 保 护力度持续加强, 社会参与有序扩大, 产生了较好 的生态效益和社会效益, 但在管理体制机制、资金 保障等方面存在一些较为突出的问题, 亟待进一步 完善(黄宝荣等, 2018; 蔵振华等, 2020)。

\section{1 国家公园体制试点的主要举措与月}

(1)统一分级的管理体制初步建立。10个试点公 园都建立了国家公园协调工作领导小组统筹推进 公园建设, 编制了建设规划并得到批复, 开展了自 然资源所有权划定和确权登记。10个试点区共整合 各类原有自然保护地约150个, 基本实现了统一行 使国家公园管理职责。

(2)资金投入有所加大。财政部将国家公园支出
纳入了林业草原生态保护恢复资金, 国家发展和改 革委员会在 “文化旅游提升工程”专项下为国家公园 体制试点建设安排了中央预算内投资。国家公园试 点区所在的省级和地方政府结合各试点的实施方 案和本省情况, 持续增加国家公园建设和运行资 金。试点以来, 10 个试点区的中央财政投入累计达 到60亿元。

(3)保护力度持续加强, 初显成效。10个试点区 范围内的受保护面积在原有保护地基础上有大幅 度增加。全方位、立体式的监测巡护体系初步建立, 管理信息化、智能化能力有较大提升, 违法破坏行 为得到有效遏制 (王天明等, 2020)。大熊猫 (Ailuropoda melanoleuca)、东北虎(Panthera tigris altaica)、雪豹 (P. uncia)、海南长臂猿 (Nomascus hainanus)等重点保护物种栖息地得到有效保护, 种 群数量稳定或有所增加, 水源涵养等生态系统服务 功能维持稳定或有所提升(Liu et al, 2020; Yang et al, 2020)。

(4)科技支撑得到加强。各试点区建立或共建国 家公园科研机构 20 余个, 合作高校和科研院所单位 达数十家, 科研成果已经开始应用于保护管理工作, 为国家公园的建设提供了有力支撑。同时, 宣传教 育、社会志愿服务规模有序扩大, 国家公园理念深 
入人心, 生态文明思想广为传播。

(5)社会参与有序扩大, 民生得到改善。国家公 园体制试点得到了各级政府和社会各界的高度重 视。各试点区将国家公园建设与精准扶贫相结合, 充分考虑地区实际, 采用设置公益岗位、提高生态 补偿标准、优化公共服务、扶持教育与就业等方式, 提高了国家公园及周边居民的收入。

\section{面临的突出问题}

国家公园体制试点是一种全新探索, 任务重、 困难大, 尽管取得积极进展, 但在管理体制机制、 资金保障等方面存在一些较为突出的问题, 亟待改 进(黄宝荣等, 2018; 藏振华等, 2020)。

(1)统筹协调机制不完善。一是区域协调机制尚 未建立，跨省的三个国家公园尽管建立了协调机制， 但仅限于各国家公园管理局与省级管理局层面的 协调。由于协调机构的层级不够, 难以解决“一园多 制”、工矿企业退出、生态搬迁等问题。二是省部 之间协调机制不完善, 目前尽管国家林业和草原局 国家公园管理办公室与 10 个试点区都建立了联络 机制, 但仅有海南热带雨林试点区建立了省和国家 局层面的协调机制, 其余9个试点区的协调机制处 于各国家公园管理局与国家公园管理办公室层面。

(2)资金保障机制不完善。首先，资金投入机制 未建立, 国家公园资金投入缺乏依据, 事权划分不 明确, 中央和省级政府不清楚各自应承担的资金投 入比例。其次，国家公园资金来源分散。目前国家 公园的建设资金来源于多个渠道, 包括国家发展和 改革委员会中央预算内的文旅提升工程投资, 财政 部的一般性转移支付和林业草原生态保护恢复资 金, 以及省市地方配套资金等, 缺少国家公园建设 的专项资金，申报体系不成熟。第三，财政资金投 入不足。国家公园是我国自然生态系统中最重要、 自然景观最独特、自然遗产最精华、生物多样性最 富集的部分, 属于最严格的保护地类型。目前, 中 央的支出力度与应承担的全民公益性资源保护责 任不匹配。地方政府在实施严格保护的同时, 短期 内没有形成新的绿色经济增长点, 财政收入受到一 定影响, 难以承担工矿企业退出、生态搬迁等需要 的大额资金。最后，企业投资和社会捐赠等无法对 财政进行有效补充。目前国家公园内自然资源利用 方面的政策制度还不完善, 允许企业等社会力量以
何种方式参与国家公园经营等问题还没有达成共 识，国家公园管理机构、地方政府、企业等各方都 存在各自的顾虑(黄宝荣等, 2018; 张海霞, 2018)。 此外, 虽然公众捐赠比试点以前出现了突破, 但还 未形成规模。

(3)保护与发展矛盾依然突出。各国家公园试点 区普遍位于经济相对落后地区。长期以来, 试点区 内的居民生计与产业发展主要依赖于当地自然资 源, 如何协调严格保护与可持续发展之间的关系, 是建立国家公园体制面临的巨大挑战(间颜等, 2021)。目前, 试点区内约有常住人口40万人, 核心 保护区内超过 2 万人没有退出, 三江源等试点区的 核心保护区内还有较大规模放牧和游牧人口, 祁连 山、大熊猫等试点区内存在较多工矿企业难以退 出。仍有相当部分的群众认为划入国家公园后生产 生活受到的限制与补偿力度之间并不匹配。此外, 试点区绿色产业还没有形成规模, 国家公园品牌价 值没有充分体现, 生态产品价值实现机制还处于探 索阶段。

\section{建议}

在国家公园体制试点已取得的经验和面临的 突出问题基础上, 根据国家公园定位, 应统筹生态 保护和经济社会发展、国家公园建设和保护地体系 完善, 合力解决重点难点问题, 把国家公园建设提 升至新的水平。

(1)完善协调管理机制。建议按照国家机构改革 职能划分, 调整完善国家公园体制建设领导小组, 建立健全统筹推进国家公园体制改革的领导体制 和工作机制。建议由国务院主管领导担任国家公园 体制建设领导小组组长, 在国家公园管理局设立领 导小组办公室, 具体负责协调推进日常工作。健全 各省和国家局、跨省之间的协调管理机制, 明确跨 省国家公园的管理条例、三定方案等审批流程, 推 动跨省联动和整体保护。明确国家公园管理机构、 监督部门、各级地方政府之间的权责边界, 提高管 理效率。

(2)完善资金保障体系。建议加快研究国家公园 的事权划分, 建立与事权相匹配的财政体制, 中央 和省级人民政府根据事权划分承担各自建设与运 行资金。建议定期开展国家公园管理有效性评估, 建立管理成效与资金投入挂钩的激励机制。各试点 
区推广特许经营管理模式、加强宣传教育, 吸引社 会投资和社会捐赠。

(3)加强思想认识建设。建议加强生态文明思想 和国家公园体制建设的学习、宣传、教育, 形成人 与自然和谐共生的理念, 增强广大干部群众对保护 自然重要性的意识，提升“给子孙后代留下珍贵的 自然遗产”的责任感和使命感。制定合理有序的工 矿企业、人口退出方案, 东北虎豹、大熊猫等短期 内难以退出的试点区设置过渡期, 加强监管, 通过 以时间换空间来解决相关问题。

(4)建立生态产品价值实现机制。建议完善国家 公园生态产品价值核算方法体系和生态补偿机制, 合理确定生态补偿的范围、对象、标准、方式、成 效考核办法等，完善地区和流域之间的横向生态补 偿机制。制定国家公园产业准入清单, 挖掘国家公 园品牌价值, 探索生态产品价值实现路径, 将生态 优势、资源优势转化为经济优势, 为实现 “绿水青 山”向“金山银山”的转化提供示范。

致谢: 感谢国家林业和草原局国家公园管理办公室 和各国家公园体制试点区提供支持，本文部分资料 来源于各试点区的评估验收报告，向报告编写人员 致谢。

\section{ORCID}

欧阳志云 (D) https://orcid.org/0000-0003-0927-0499

徐卫华 (1D) https://orcid.org/0000-0001-7622-7365

藏振华 (iD https://orcid.org/0000-0002-6643-9468

\section{参考文献}

Huang BR, Wang Y, Su LY, Zhang CL, Cheng DW, Sun J, He SY (2018) Pilot programs for National Park system in China: Progress, problems and recommendations. Bulletin of Chinese Academy of Sciences, 33, 768 5. (in Chinese with English abstract) [黄宝荣, 王毅, 苏利阳, 张丛林, 程 多威, 孙晶, 何思源 (2018) 我国国家公园体制试点的进
展、问题与对策建议. 中国科学院院刊, 33, 76-85.]

Liu H, Ma HD, Cheyne SM, Turvey ST (2020) Recovery hopes for the world's rarest primate. Science, 368, 1074.

Tang FL, Yan Y, Liu WG (2019) Construction progress of National Park system in China. Biodiversity Science, 27, 123-127. (in Chinese with English abstract) [唐芳林，用颜， 刘文国 (2019) 我国国家公园体制建设进展. 生物多样 性, 27, 123-127.]

Wang TM, Feng LM, Yang HT, Bao L, Wang HF, Ge JP (2020) An introduction to Long-term Tiger-Leopard Observation Network based on camera traps in Northeast China. Biodiversity Science, 28, 1059066. (in Chinese with English abstract) [王天明，冯利民，杨海涛，鲍蕾，王 红芳, 葛剑平 (2020) 东北虎豹生物多样性红外相机监 测平台概述. 生物多样性, 28, 1059-1066.]

Yan Y, Tang FL, Tian YC, Jin K (2021) On implementation path of the strictest conservation policies in National Park management. Biodiversity Science, 29-1283 (in Chinese with English abstract) [间颜, 唐芳林, 田勇臣, 金 崑 (2021) 国家公园最严格保护的实现路径. 生物多样 性, 29, 123-128.]

Yang B, Qin SY, Xu WS, Busch J, Yang XY, Gu XD, Yang ZS, Wang B, Dai Q, Xu Y (2020) Gap analysis of giant panda conservation as an example for planning China's National Park system. Current Biology, 30, 1287-1291.

Zang ZH, Zhang D, Wang N, Du A, Kong LQ, Xu WH, Ouyang ZY (2020) Experiences, achievement, problems and recommendations of the first batch of China's National Park system pilots. Acta Ecologica Sinica, 40, 8839-8850. (in Chinese with English abstract) [閭振华, 张多, 王楠, 杜傲, 孔令桥, 徐卫华, 欧阳志云 (2020) 中国首批国家公园体 制试点的经验与成效、问题与建议. 生态学报, 40, 8839-8850.]

Zhang HX (2018) Research on Concession Mechanisms for Commercial Services in China's National Parks. China Environment Publishing Group, Beijing. (in Chinese) [张海 霞 (2018) 中国国家公园特许经营机制研究. 中国环境 出版集团, 北京.] 